\title{
Comparative analysis of the genes encoding 23S-5S rRNA intergenic spacer regions of Lactobacillus casei-related strains
}

\author{
H. Chen, C. K. Lim, Y. K. Lee and Y. N. Chan
}

Author for correspondence: C. K. Lim. Tel: +65 874 3332. Fax: +65 7766872. e-mail: miclimck@nus.edu.sg

Department of

Microbiology, Faculty of Medicine, National University of Singapore, Singapore, Lower Kent Ridge Road, Singapore 119260
In this study, investigations into the 235-5S rRNA intergenic spacer regions (ISRs) of the Lactobacillus casei group were performed. A $1.6 \mathrm{~kb}$ fragment, from Lactobacillus paracasei strain ATCC 27092, containing part of the 5 S rRNA gene (60 bp), the 5S-23S spacer region (198 bp) and part of the 235 rRNA gene (1295 bp) was cloned and sequenced (GenBank no. AF098107). This fragment was used as a probe to determine the rRNA restriction fragment length polymorphism (RFLP) patterns of nine strains belonging to the Lactobacillus casei group, along with four other non-Lactobacillus casei lactobacilli species. A pair of PCR primers, 23-FI and 5-Ru, was designed and used for PCR amplification of the 23S-5S rRNA ISRs of these strains. The ISR length and sequence polymorphisms provided additional information for the taxonomic study of the Lactobacillus casei group. The spacer-length polymorphism of Lactobacillus rhamnosus was distinct from those of the other strains and this observation is consistent with the classification of Lactobacillus rhamnosus proposed by Mori et al. For all Lactobacillus casei and Lactobacillus paracasei strains, two major bands (approx. 250 and 170 bp in size) were obtained except in the case of Lactobacillus paracasei subsp. tolerans strain NCIMB 9709', which yielded only one amplified product (250 bp). The sequencing data of the PCR products of seven well-characterized Lactobacillus casei and Lactobacillus paracasei strains revealed the presence of a $76 / 80 \mathrm{bp}$ insertion/deletion with some random, single-base substitutions between the longer and shorter spacers for each respective strain. A few base variations were also detected within different strains in this group although the overall sequence similarity was very high (95.9-99.5\%). The rRNA RFLP and the spacer sequence of Lactobacillus casei type strain ATCC $393^{\top}$ exhibited unique identities in this cluster. On the other hand, Lactobacillus casei strain ATCC 334 showed a high level of similarity with the other Lactobacillus casei strains tested. These observations lend some support to the request for the reassignment of strain ATCC 334 as the neotype of Lactobacillus casei subsp. casei in place of strain ATCC $393^{\top}$.

Keywords: Lactobacillus casei, Lactobacillus paracasei, Lactobacillus rhamnosus, 23S-5S intergenic rRNA spacer, length and sequence polymorphism

Abbreviations: ISR, intergenic spacer region; LISR, long intergenic spacer region; RAPD, random amplified polymorphic DNA; RFLP, restriction fragment length polymorphism; SISR, short intergenic spacer region.

The GenBank accession numbers for the Lactobacillus nucleotide sequences reported in this paper are as follows: AF098107 (Lactobacillus paracasei strain ATCC 27092, cloned fragment); AF098108 (Lactobacillus paracasei strain ATCC 27092, SISR); AF097704 (Lactobacillus paracasei strain NCIMB 9713, LISR); AF097705 (Lactobacillus paracasei strain NCIMB 9713, SISR); AF097702 (Lactobacillus casei strain ATCC 334, LISR); AF097703 (Lactobacillus casei strain ATCC 334, SISR) 


\section{INTRODUCTION}

The Lactobacillus casei-related group contains a number of well-known lactobacilli found in many habitats (dairy products, wine, silage, sewage and the human intestinal tract and mouth). This species is poorly defined and the classification of the Lactobacillus casei group is not yet stable. The debates over the classification of this species have been reviewed recently (Mori et al., 1997). The taxonomic reassignments were based mainly on DNA-DNA hybridization (Dicks et al., 1996; Collins et al., 1989), rRNA sequence analysis (Collins et al., 1991) or rRNA-targeted probes (Ferrero et al., 1996; Hertel et al., 1993) and whole-cell protein analysis (Dellaglio et al., 1991). Recently, ribotyping was used (Zhong et al., 1998) to differentiate between lactobacilli strains recovered from the vaginas of healthy premenopausal women.

In prokaryotes, the rRNA genetic loci contain the genes for all three rRNA subunits (the 16S, 23S and 5S genes) and each rRNA gene is separated by an intergenic spacer region (ISR). These ISRs exhibit a large degree of sequence and length variation at the levels of genus and species (Barry et al., 1991; Gürtler $\&$ Stanisich, 1996). Within a single genome there are frequently multiple rRNA genetic loci. Spacer regions found within these loci also show a significant degree of variation in length and sequence. It was suggested (Barry et al., 1991) that the spacer regions should be under minimal selective pressure during evolution and therefore should vary more extensively than sequences within genes that have functional roles. Sequence divergence between different species within a genus has already been reported (Frothingam \& Wilson, 1994).

Recently, length and sequence polymorphisms in the spacers within the rrn loci have been used to discriminate between species of lactobacilli, as well as to identify different dairy and probiotic lactic acid bacteria (Tilsala-Timisjarvi \& Alatossava, 1997; Nakagawa et al., 1994). However, the data available on the ISRs of lactobacilli are not sufficient and all the previous studies targeted the 16S-23S rRNA ISRs. In fact, most of the work on rDNA spacer polymorphisms was done to identify or detect the bacteria between and within species (Jensen et al., 1993; Gürtler $\&$ Stanisich, 1996). The aim of this work was to clone, sequence and perform intergroup comparisons of the 5S-23S rRNA spacer genes from Lactobacillus caseirelated strains. A heterologous probe which carries the $5 \mathrm{~S}$, the $5 \mathrm{~S}-23 \mathrm{~S}$ spacer region and part of the 23S rRNA genes from Salmonella typhi (ATCC 167) (Zhu et al., 1996) was used to locate the gene in Lactobacillus casei. The clone obtained was sequenced. A pair of primers flanking the spacer region was designed based on the sequences and used for amplification of the $5 \mathrm{~S}-23 \mathrm{~S}$ spacer regions from nine different well-characterized Lactobacillus casei-related strains. The genetic relationship between these strains was investigated by means of ISR sequence alignment and inter- and intraspecific variation analysis. In addition, the use of the $23 \mathrm{~S}-5 \mathrm{~S}$ spacer as a genetic marker in taxonomic studies was evaluated.

\section{METHODS}

Bacterial strains and culture conditions. The strains used in this study are shown in Table 1. Lactobacilli were cultured in MRS (Man-Rogosa-Sharpe) medium (Oxoid) at $37^{\circ} \mathrm{C}$. All the lactobacilli were phenotypically tested by using the API $50 \mathrm{CHL}$ system according to the instructions of the manufacturer. Escherichia coli TG1, the host for recombinant plasmids, was cultured in Luria-Bertani (LB) broth at $37^{\circ} \mathrm{C}$ with shaking. Stock cultures were maintained in soft agar $(0.6 \%$ agar $)$ stabs at $4{ }^{\circ} \mathrm{C}$. Frozen glycerol cultures were used for long-term storage.

Preparation of DNA. Genomic DNA from Lactobacillus cells was prepared as described previously (Stahl et al., 1990), with some modification. Cells were harvested from 250 $\mathrm{ml} / 18 \mathrm{~h}$ cultures, washed once, resuspended in $20 \mathrm{ml}$ TES (50 mM Tris/HCl, $50 \mathrm{mM} \mathrm{NaCl}, 1 \mathrm{mM}$ EDTA, $\mathrm{pH} \mathrm{8.0)}$ containing $20 \mathrm{mg}$ lysozyme ml-1 and then incubated for $2 \mathrm{~h}$ at $37^{\circ} \mathrm{C}$. For different strains, the incubation time may vary. After the addition of $2.5 \mathrm{ml} 5 \% \mathrm{NaCl}, 5 \mathrm{ml} 10 \%$ SDS and $12.5 \mathrm{ml}$ TES, the cell suspension was incubated at $37^{\circ} \mathrm{C}$ for another $30 \mathrm{~min}$. Deproteinization was achieved by extraction twice with an equal volume of phenol followed by removal of phenol, once, with chloroform. DNA was precipitated by adding $0 \cdot 1$ vol. $3 \mathrm{M}$ sodium acetate $(\mathrm{pH} 5 \cdot 2)$ and 2 vols ice-cold ethanol, washing in 90 and $70 \%$ ethanol, drying and resuspension in TE $(10 \mathrm{mM}$ Tris $/ \mathrm{HCl}, 1 \mathrm{mM}$ EDTA, $\mathrm{pH}$ 8.0).

Large-scale preparation of plasmid DNA was carried out using the Wizard Plus Maxiprep DNA purification system (Promega). The rapid plasmid mini-preparation procedure was as described elsewhere (Ish-Horowicz \& Burke, 1981). For sequencing purposes, the Wizard Plus Miniprep DNA purification system was used, according to the manufacturer's instructions, to obtain high-purity plasmid DNA.

Restriction endonuclease digestion, gel electrophoresis and hybridization. Chromosomal DNA from Lactobacillus paracasei ATCC 27092 was completely cleaved with restriction enzymes (New England Biolabs) and fractionated on $0.8 \%$ agarose gel. The DNA fragments were then transferred on to a nylon membrane (Hybond- $\mathrm{N}^{+}$; Amersham) by conventional Southern blotting. The probe containing the $5 \mathrm{~S}$ rRNA gene, the $23 \mathrm{~S}-5 \mathrm{~S}$ spacer and part of the $23 \mathrm{~S}$ rRNA gene of $S$. typhi was recovered from lowmelting-point gel after digestion of pZQ12 with EcoRI. Labelling of the probe and the size marker, hybridization and detection of the result were carried out by using the ECL kit (PRN 3001; Amersham) according to the manufacturer's protocol.

Cloning and transformation. Ligation and transformation of competent $E$. coli TG1 were carried out as described previously (Sambrook et al., 1989). The transformants were screened on LB agar plates containing $50 \mu \mathrm{g}$ ampicillin $\mathrm{ml}^{-1}$

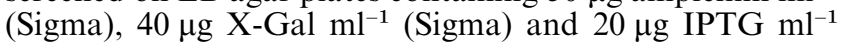
(Sigma).

Sequencing. A set of overlapping deletion subclones was constructed by using the Erase-a-base system (Promega), according to the manufacturer's instructions. The ligated products were used to transform competent $E$. coli TG1. Only the appropriately sized subclones were sequenced. The insert fragment of the recombinant plasmid was sequenced using Sequenase (version 2.0; USB) with the pUC18 forward 
Table 1. Bacterial strains used in this study and their PCR products by $23-\mathrm{FI}$ and $5-\mathrm{Ru}$

\begin{tabular}{|c|c|c|c|}
\hline No. & Strain & Source & Spacer length (bp) \\
\hline 1 & Lactobacillus casei subsp. casei ATCC 334 & Emmental cheese & 250 and 170 \\
\hline 2 & Lactobacillus casei subsp. casei NCIMB 8822 & Human saliva & 250 and 170 \\
\hline 3 & Lactobacillus casei subsp. casei ATCC $393^{\mathrm{T}}$ & Cheese; NCIMB 11970 & 250 and 170 \\
\hline 4 & Lactobacillus paracasei ATCC 27092 & Yakult; DSM 20312 & 250 and 170 \\
\hline 5 & Lactobacillus paracasei NCIMB 8001 & Unknown; ATCC 10746 & 250 and 170 \\
\hline 6 & $\begin{array}{l}\text { Lactobacillus paracasei subsp. tolerans } \\
\text { NCIMB } 9709^{\mathrm{T}}\end{array}$ & Pasteurized milk; ATCC $25599^{\mathrm{T}}$ & 250 \\
\hline 7 & $\begin{array}{l}\text { Lactobacillus paracasei subsp. paracasei } \\
\text { NCIMB } 9713\end{array}$ & Milking machine; ATCC 25598 & 250 and 170 \\
\hline 8 & Lactobacillus rhamnosus NCIMB $6375^{\mathrm{T}}$ & Unknown; ATCC $7469^{\mathrm{T}}$ & 170 and 160 \\
\hline 9 & Lactobacillus rhamnosus ATCC 53103 & Human & 170 and 160 \\
\hline 10 & $\begin{array}{l}\text { Lactobacillus delbrueckii subsp. bulgaricus } \\
\text { NCIMB } 11778^{\mathrm{T}}\end{array}$ & Yoghurt; ATCC 11842 & 125 \\
\hline 11 & Lactobacillus acidophilus NCIMB $8690^{\mathrm{T}}$ & Human; ATCC $4356^{\mathrm{T}}$ & 125 \\
\hline 12 & Lactobacillus fermentum Coll. mir* & Healthy food & 120 \\
\hline 13 & Lactobacillus fermentum Coll. b1* & Yoghurt & 120 \\
\hline 14 & Lactobacillus plantarum Coll. lyk* & Fermented milk & 125 \\
\hline 15 & Lactobacillus plantarum ATCC $14917^{\mathrm{T}}$ & Pickled cabbage; NCIMB $11974^{\mathrm{T}}$ & 125 \\
\hline
\end{tabular}

* Species identification was confirmed by using the API 50 CHL kit. Coll, Collection strains deposited as departmental strains and used for PCR.

\section{$23 S$ rDNA}

$23-\mathrm{F} 1$

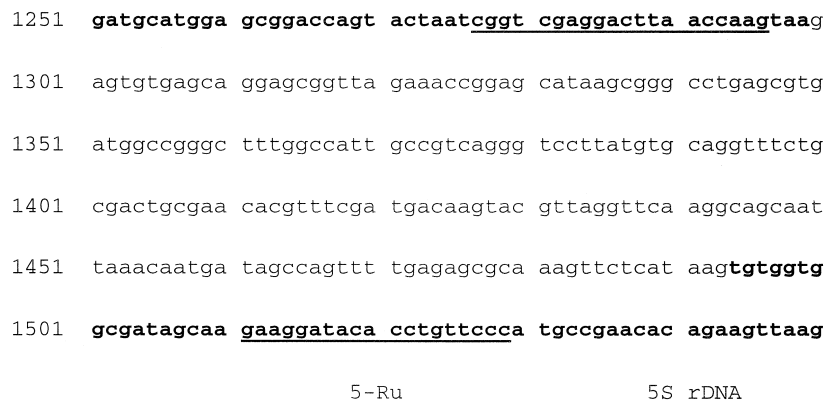

Fig. 1. Sequence of the $P C R$ primers and its corresponding region in the $1.6 \mathrm{~kb}$ cloned insert (GenBank no. AF098107). Sequences corresponding to the two primers are underlined. Sequences from the $23 \mathrm{~S}$ and $5 \mathrm{~S}$ rRNA genes are shown in bold.

and reverse primers provided with the kit. The reaction conditions were as described in the booklet accompanying the kit. Computer searches of EMBL/GenBank were performed using BLAST network services.

Oligonucleotide primers and PCR. A pair of primers, 23-Fl and 5-Ru, which flanks the $5 \mathrm{~S}-23 \mathrm{~S}$ rRNA spacer region, was designed after comparing the sequence obtained for the Lactobacillus paracasei ATCC 27092 rRNA gene with the sequences reported in GenBank. The sequences of the primers were as follows: 5'-CGGTCGAGGACTTAACCAAG-3' for 23-Fl (nucleotides of 23S rRNA gene) and 5'GGGAACAGGTGTATCCTTC-3' for 5-Ru (complementary sequence of 5S rRNA gene) (Fig. 1) The PCR was performed by using SuperTaq polymerase (HT Biotechnology) in a DNA thermal cycler (Hybaid OmniGene). A typical reaction mixture $(50 \mu \mathrm{l})$ for the PCR consisted of
$10 \mathrm{mM}$ Tris/ $\mathrm{HCl}, \mathrm{pH} 9 \cdot 0,1.5 \mathrm{mM} \mathrm{MgCl}_{2}, 50 \mathrm{mM} \mathrm{KCl}$, $0.1 \%$ Triton $\mathrm{X}-100,0.01 \%(\mathrm{w} / \mathrm{v})$ gelatin, $8 \mu \mathrm{M}$ primer, $200 \mu \mathrm{M}$ dNTP, $2 \mu \mathrm{l}$ template DNA and $1 \mathrm{U}$ SuperTaq polymerase. The reaction tubes were overlaid with drops of mineral oil. The amplification was carried out at $95^{\circ} \mathrm{C}$ for 30 $\mathrm{s}, 53{ }^{\circ} \mathrm{C}$ for $45 \mathrm{~s}$ and then $72{ }^{\circ} \mathrm{C}$ for $1 \mathrm{~min}$. This was repeated for 35 cycles. The program also included a preincubation at $95^{\circ} \mathrm{C}$ for $5 \mathrm{~min}$ before the first cycle and an incubation at $72{ }^{\circ} \mathrm{C}$ for $5 \mathrm{~min}$ after the last cycle. Ten to twenty microlitres of the PCR mixtures were electrophoresed in $3 \%$ agarose gel with ethidium bromide.

Sequencing of PCR-amplified 23S-5S rRNA gene spacer region. PCR products were analysed using agarose gel electrophoresis. If different sizes of DNA fragments were found, the major bands were excised from the low-meltingpoint gel and purified with ultrapure phenol and dissolved in distilled water or TE. This DNA was used as a template in a second round of the PCR. The amplification product was then purified again and used for sequencing purposes. The spacer-region genes were sequenced directly from both ends, without cloning, on an automated sequencer (model 310, Genetic analyser, ABI) by using the Prism BigDye Terminator Ready Reaction Cycle Sequencing kit (ABI). The nucleotide sequences of the ISRs of lactobacilli strains were aligned by MEGALIGN, using the CLUSTAL method (Higgins \& Sharp, 1989) to give maximum homology.

\section{RESULTS AND DISCUSSION}

\section{Cloning of the rRNA genes of Lactobacillus paracasei ATCC 27092}

The rRNA genes in the EcoRI-cleaved fragments were located by Southern hybridization with the heterologous rRNA gene probe from pZQ12 (Zhu et al., 1996) which carries the 5S rRNA gene, the $23 \mathrm{~S}-5 \mathrm{~S}$ spacer and part of the $23 \mathrm{~S}$ rRNA gene of $S$. typhi. One 
(a)

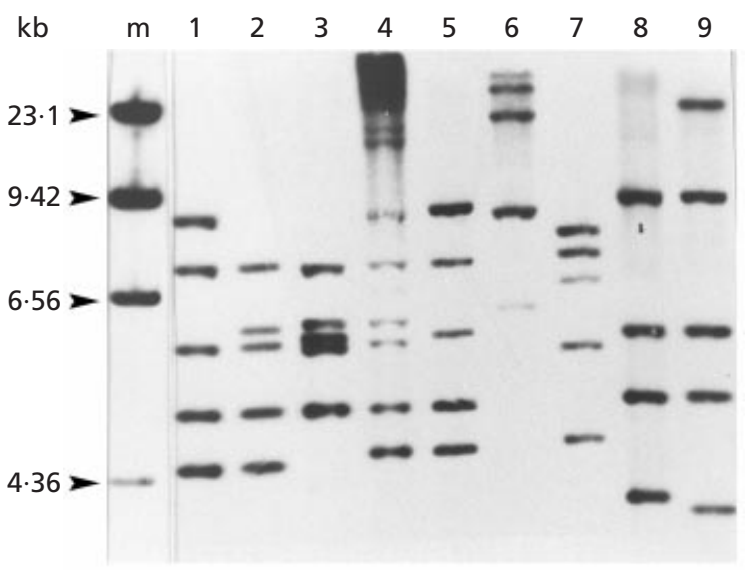

(b)

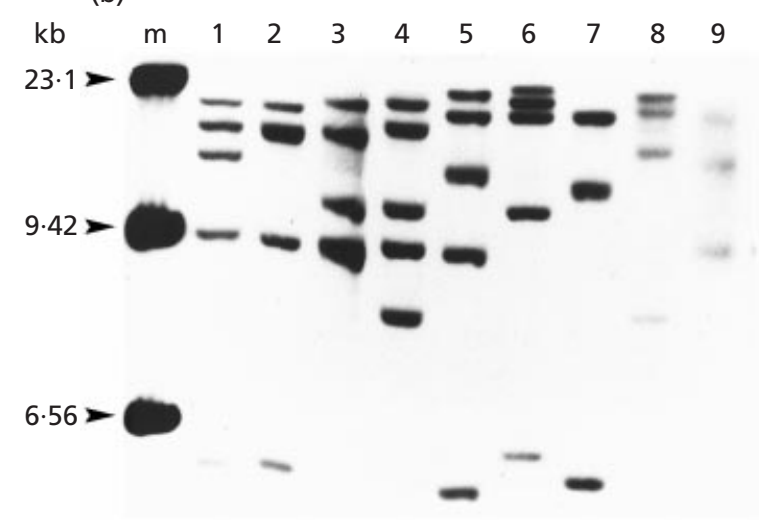

Fig. 2. Ribotyping of $L$. casei strain rRNA restriction fragments of genomic DNA digested with BamHI (a) and Pstl (b) using the cloned $1.6 \mathrm{~kb}$ Hindlll insert as a probe. Lanes: $\mathrm{m}, \lambda$ Hindlll marker; 1, L. paracasei ATCC 27092; 2, L. paracasei NCIMB 8001; 3, L. casei NCIMB 8822; 4, L. paracasei NCIMB 9713; 5, L. casei ATCC $334 ; 6, L$. casei ATCC $393^{\top} ; 7$, L. casei subsp. tolerans NCIMB 9709'; 8, L. rhamnosus ATCC 53103; 9, L. rhamnosus NCIMB $6375^{\top}$.

of the hybridizing bands, approx. $6 \mathrm{~kb}$ in size, was ligated with EcoRI-cleaved dephosphorylated pUC18. It was found that a $1.6 \mathrm{~kb}$ HindIII fragment within the $6 \mathrm{~kb}$ insert yielded the most intense hybridizing band against the previous heterologous probe, when the $6 \mathrm{~kb}$ insert was further digested and hybridized with the probe. Thus, the $1.6 \mathrm{~kb}$ HindIII fragment was isolated and religated with HindIII-cleaved, dephosphorylated pUC18. This cloned insert was labelled and used as a probe against Lactobacillus paracasei ATCC 27092 genomic DNA completely cleaved with HindIII. Two hybridizing bands of the same intensity were obtained: one was $1.6 \mathrm{~kb}$ in size, as expected, while the other band was approximately $1.5 \mathrm{~kb}$ in size. The cloned insert DNA was therefore confirmed to be from Lactobacillus paracasei subsp. paracasei ATCC 27092.

The $1.6 \mathrm{~kb}$ HindIII insert was sequenced and the data were compared with the GenBank database. The results indicated that the cloned fragment contains part of the 23S rRNA gene (1295 bp), the 23S-5S spacer region (198 bp) and part of the $5 \mathrm{~S}(60 \mathrm{bp})$ rRNA gene. The partial sequences encoding the $23 \mathrm{~S}$ and 5S rRNA genes were compared with the rRNA data on other lactobacilli in GenBank. According to the published data from GenBank, the 23S rRNA gene of lactobacilli is $2852-2909 \mathrm{bp}$ in length while $5 \mathrm{~S}$ is $117 \mathrm{bp}$ long. The partial sequence encoding the $23 \mathrm{~S}$ rRNA of Lactobacillus paracasei ATCC 27092 shares $90 \%$ homology with the corresponding parts of the 23S rRNA gene of Lactobacillus delbrueckii (2852 bp; GenBank no. X68426) and the Lactobacillus confusus gene (2852 bp; GenBank no. X68035). The partial rRNA gene encoding $5 \mathrm{~S}$ has $96 \%$ homology with the first $60 \mathrm{bp}$ of the 5S rRNA of Lactobacillus brevis (GenBank no. X02026), $94 \%$ homology with Lactobacillus delbrueckii (GenBank no. X15425) and 93\% homology with Lactobacillus plantarum (GenBank no. X12886).

\section{rRNA RFLP by hybridization with the homologous probe}

The ribopatterns obtained using the $1.6 \mathrm{~kb}$ HindIII fragment as a homologous probe against Lactobacillus casei-group strain genomic DNA digested by $B a m \mathrm{HI}$ and PstI are shown in Fig. 2, parts (a) and (b), respectively. These two enzymes generated the same powers of differentiation in the ribotyping of Lactobacillus casei-group strains. The ribotyping carried out also demonstrated that the rRNA RFLP of strain ATCC $393^{\mathrm{T}}$ generated by BamHI and PstI formed patterns divergent from those of the other strains tested, whereas the ribotyping patterns of strain ATCC 334 shared two to four restriction bands with the other strains in this group, indicating their close relationship.

\section{PCR of the 23S-5S rRNA ISR from DNA of Lactobacillus casei-related strains}

To assess the degree of polymorphism in the $23 \mathrm{~S}-5 \mathrm{~S}$ spacer region among different lactobacilli, particularly the members of the Lactobacillus casei group, a pair of primers, 23-Fl and 5-Ru, was designed on the basis of the sequence of the $1.6 \mathrm{~kb}$ HindIII fragment and used to amplify the spacer region of the $23 \mathrm{~S}-5 \mathrm{~S}$ rRNA genes from six lactobacilli species, including nine strains belonging to the Lactobacillus casei group listed in Table 1. A $250 \mathrm{bp}$ PCR product was expected for Lactobacillus paracasei strain ATCC 27092 according to the sequence illustrated in Fig. 1. However, two major amplicons approximately 250 and $170 \mathrm{bp}$ long were obtained (lane 2, Fig. 3). The same PCR patterns were observed for the other five Lactobacillus caseirelated strains (lanes 3-7, Fig. 3) while Lactobacillus paracasei subsp. tolerans strain NCIMB $9709^{\mathrm{T}}$ yielded only the $250 \mathrm{bp}$ product (lane 8, Fig. 3). Unlike the other seven Lactobacillus casei and Lactobacillus paracasei strains, two Lactobacillus rhamnosus strains yielded two smaller bands (165 and $170 \mathrm{bp}$ ). Two Lactobacillus plantarum strains had three major 


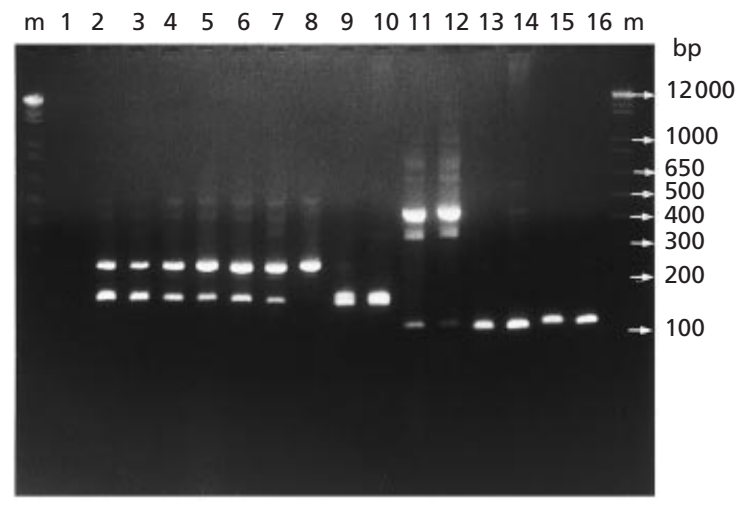

Fig. 3. $P C R$ products of amplified 23S-5S rRNA gene spacer regions obtained from different $L$. casei-related strains using primers 23-FI and 5-Ru. Lanes: $\mathrm{m}, 1 \mathrm{~kb}$ DNA ladder (Gibco BRL); 1, negative control; 2, L. paracasei ATCC 27092; 3, L. casei NCIMB 8822; 4, L. paracasei NCIMB 9713; 5, L. paracasei NCIMB $8001 ; 6$, L. casei ATCC 334; 7, L. casei ATCC $393^{\top} ;$, , L. paracasei subsp. tolerans NCIMB $9709^{\top} ; 9$, L. rhamnosus NCIMB $6375^{\top} ; 10$, L. rhamnosus GG; 11, L. plantarum Coll. lyk; 12, L. plantarum ATCC $14917^{\top}$; 13, L. fermentum Coll. mir; 14, L. fermentum Coll. bl; 15, L. delbrueckii subsp. bulgaricus NCIMB $11778^{\top} ; 16, L$. acidophilus NCIMB $8690^{\top}$. Coll., Collection strains deposited as departmental strains and used for the PCR.

amplicons of 400, 350 and 125 bp (lanes 11 and 12, Fig. 3 ) and two Lactobacillus fermentum strains had only one amplicon of $120 \mathrm{bp}$ (lanes 13 and 14, Fig. 3). The PCR-amplified products of Lactobacillus acidophilus and Lactobacillus delbrueckii were almost the same length (120 bp; lanes 15 and 16, Fig. 3). The 23S-5S ISR sequences of some other lactobacilli and different genera have also been determined. The 23S-5S ISR of Lactobacillus helveticus is $71 \mathrm{bp}$ long (GenBank no. Z75484); Lactobacillus acidophilus is 69 bp (GenBank no. Z75474) or $71 \mathrm{bp}$ long (GenBank no. Z75468) and that of Lactobacillus bulgaricus is $71 \mathrm{bp}$ long (GenBank no. Z75477). The 23S-5S spacer of Lactococcus lactis is 96 bp long (GenBank no. Z75493), the Leuconostoc mesenteroides subsp. dextranicum spacer is $99 \mathrm{bp}$ long (GenBank no. Z75489), Leuconostoc mesenteroides has a $99 \mathrm{bp}$ spacer (GenBank no. Z75486) and Streptococcus thermophilus has one that is $83 \mathrm{bp}$ in length (GenBank no. Z83759).

\section{Sequence analysis of the 23S-5S ISRs of Lactobacillus casei-related group}

PCR products of 250 and $170 \mathrm{bp}$ from the 23S-5S rRNA gene-spacer regions of six Lactobacillus casei and Lactobacillus paracasei strains and the single $250 \mathrm{bp}$ amplicon of Lactobacillus paracasei NCIMB $9709^{\mathrm{T}}$ were sequenced. Our 23S-5S long spacer-region sequence data for Lactobacillus casei ATCC $393^{\mathrm{T}}$ differed at one position (a $\mathrm{C}$ instead of a $\mathrm{G}$ at $88 \mathrm{bp}$ ) from the published data reported (GenBank no. Z75480). The nucleotide sequences of the long intergenic spacer region (LISR) and the short intergenic spacer region (SISR) were 198 and $122 \mathrm{bp}$ long, respectively, by sequence determination. The sequence

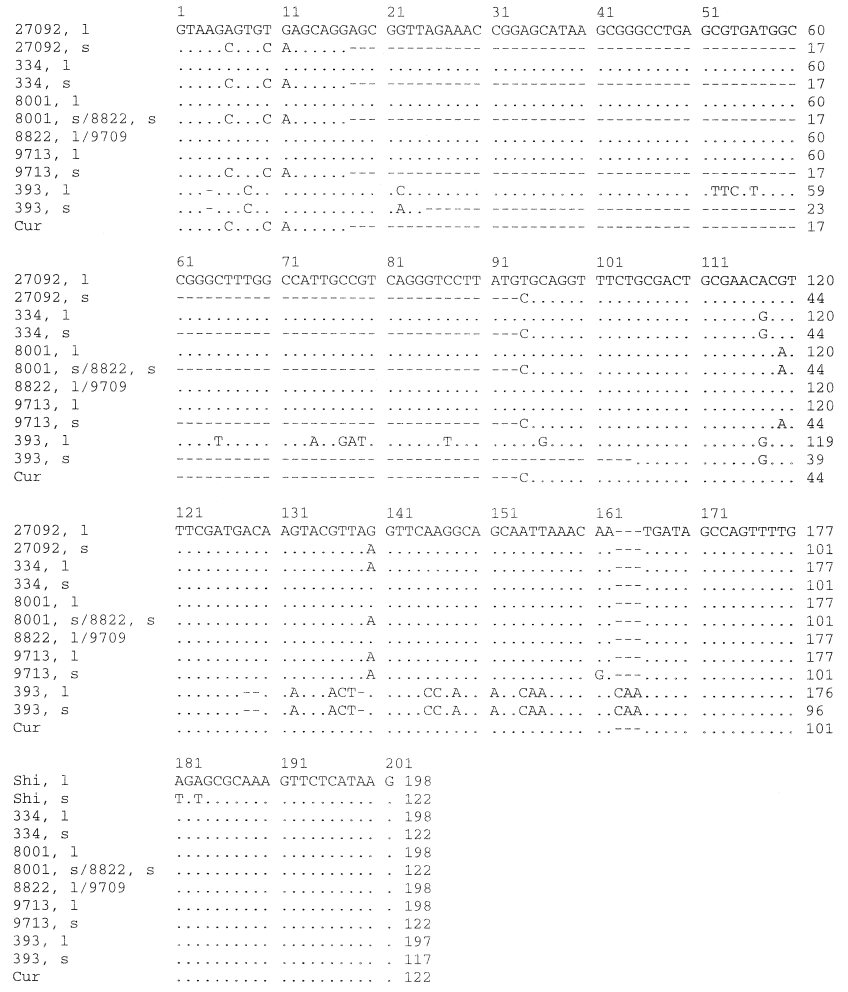

Fig. 4. Alignment of nucleotide sequences obtained from two forms of 23S-5S rRNA intergenic spacer region from certain $L$. casei-related strains, including the published corresponding sequence of $L$. curvatus ARILAIT LC59 (GenBank no. Z75471). Alignment of these sequences required the introduction of multiple gaps (shown as hyphens) to maximize the homology. The bases that are identical to those of the top line are indicated by dots. 27092, L. paracasei ATCC 27092; 334, L. casei ATCC 334; 8001, L. paracasei NCIMB 8001; 8822, L. casei NCIMB $8822 ; 9709, L$. casei subsp. tolerans NCIMB $9709^{\top} ; 9713, L$. paracasei NCIMB 9713; 393, L. casei ATCC $393^{\top}$; Cur, L. curvatus LC59 (GenBank no. Z75471); 1, LISR; s, SISR.

alignment is shown in Fig. 4. The likely ends of the $23 \mathrm{~S}$ and 5S rRNA subunits were deduced after comparison with the published data from GenBank, particularly in the case of the published sequence for the Lactobacillus casei ATCC $393^{\mathrm{T}}$ 23S-5S spacer (GenBank no. Z75480). When sequenced, the single amplicon from Lactobacillus paracasei subsp. tolerans NCIMB $9709^{\mathrm{T}}$ turned out to be $198 \mathrm{bp}$ in length. Lactobacillus casei ATCC $393^{\mathrm{T}}$ was found to be different from the other strains in the group and its unique identity is discussed later.

Comparison of the sequences of either the LISR or the SISR cluster indicated that these sequences are highly conserved. The sequences of SISR of Lactobacillus casei subsp. casei NCIMB 8822 and Lactobacillus paracasei NCIMB 8001 are identical; a similar situation prevails for the LISR of Lactobacillus casei subsp. casei NCIMB 8822 and the single spacer of Lactobacillus paracasei subsp. tolerans NCIMB $9709^{\mathrm{T}}$. The LISR sequences share 98.0-99.5\% identity, while the SISR sequences share $95 \cdot 9-99 \cdot 2 \%$ identity. The 
main difference between the long and short spacers of these strains was the presence of a $76 \mathrm{bp}$ insertion/ deletion at position $18 \mathrm{bp}$ together with some single or set base differences. At the junction with the extra segment there are a few base differences between the LISR and the SISR of a particular strain. This observation is also applicable to strain ATCC 393 in spite of its lower level of similarity with the other strains. Some of these point substitutions were unique to a single PCR product, indicating that such sequence alterations were random events and probably due to random mutations or PCR errors. For example, at position $161 \mathrm{bp}$, the A nucleotide was present in all the strains except for the SISR of Lactobacillus paracasei NCIMB 9713 (which contained a G). However, other differences seem representative of subspecies. At position $119 \mathrm{bp}$, there is an A nucleotide in both the LISR and SISR of Lactobacillus paracasei NCIMB 8001 and the LISR of Lactobacillus paracasei NCIMB 9713, whereas all the others have a G. A similar change occurs at position $117 \mathrm{bp}$ in both the LISR and the SISR of Lactobacillus casei strain ATCC 334. Interestingly, all the substitutions at the junction of the gap between the long and short spacers remained the same for most of the strains. At position $6 \mathrm{bp}$, a nucleotide $\mathrm{C}$ in SISR replaced the A of LISR and CA appeared instead of TG at positions $10 / 11 \mathrm{bp}$. After the gap, a $\mathrm{C}$ in the short spacers replaced all the $\mathrm{T}$ in the long fragments. Given the degree of sequence variation observed in our study, the spacer region may differ between different strains of a species. This is contrary to the observation (Berthier \& Ehrlich, 1998) that the 16S-23S spacer sequences of different strains within a species (i.e. Lactobacillus plantarum, Lactobacillus paraplantarum, Lactobacillus pentosus, Lactobacillus curvatus, Lactobacillus graminis and Lactobacillus sakei) are $100 \%$ identical.

Sequence differences could be incorporated into different copies of the spacer within the genome, as well as differences between isolates and also possible PCR artefacts. To eliminate the possibility of artefacts, a second round of the PCR was carried out. Reamplification of the purified longer fragment produced only one intense band of the same size, without any smaller bands. Hybridization of the HindIII $1.6 \mathrm{~kb}$ fragment with the total DNA of ATCC 27092 digested with HindIII yielded two bands of about 1.5 and $1.6 \mathrm{~kb}$ (there is no HindIII site within the $1.6 \mathrm{~kb}$ fragment). If there were only one copy of the $r \mathrm{rn}$ operon, then only one hybridizing band of $1.6 \mathrm{~kb}$ should be seen when the $1.6 \mathrm{~kb}$ HindIII fragment was used as a probe against the complete HindIII digest of Lactobacillus paracasei ATCC 27092 genomic DNA. These results excluded the possibility that the smaller fragment was generated by an artefact of the PCR amplification in which the extra segment was looped out. A similar approach was used for the 16S-23S spacer of Enterococcus faecalis (Hall, 1994). This finding confirmed that at least two forms of rRNA operon are present in this species. It has been reported that in most bacterial species the rRNA genes are present in more than one copy per bacterial genome (Barry et al., 1991) and that the ISRs often differ in both sequence and length. Heterogeneity in the 23S-5S ISR region within one organism has been observed in Saccharomonospora azurea $\mathrm{K} 161^{\mathrm{T}}$ (Yoon et al., 1997), in which three $r r n$ loci were investigated. The results revealed that the $23 \mathrm{~S}-5 \mathrm{~S}$ sequences of $r r n A$ and $r r n C$ were identical, whereas the other $\operatorname{rrn} A$ had a spacer that was $2 \mathrm{bp}$ longer. At present, the exact number of rRNA operons for Lactobacillus is still unknown. Lactobacillus lactis has been shown to contain six rrn operons (Tulloch et al., 1991); Streptococcus thermophilus, five to six (Pebay et al., 1992); Lactobacillus acidophilus, at least four (Roussel et al., 1987); and Lactobacillus plantarum, at least five $\mathrm{rrn}$ operons (Chevallier et al., 1994). As two ISR amplicons were obtained, we suggest that at least two different sets of rRNA operons are present in this Lactobacillus casei species. This phenomenon was also reported for the $16 \mathrm{~S}-23 \mathrm{~S}$ spacer regions of the other micro-organisms (Yoon et al., 1997; Gürtler \& Barrie, 1995; Whiley et al., 1995). From this analysis, we have concluded that the 23S-5S rRNA spacer regions of each of the two sets of rrn operons of Lactobacillus casei-related strains are very similar in sequence whereas Lactobacillus casei strain ATCC $393^{\mathrm{T}}$ showed unique identity in the cluster. Lactobacillus paracasei subsp. tolerans strain NCIMB $9709^{\mathrm{T}}$ may contain a spacer-region sequence that is similar and of the same length within different rRNA operons. This assumption is also based on the fact that the single PCR-amplified band of strain NCIMB $9709^{\mathrm{T}}$ showed a brighter intensity. Although the PCRs were not carried out with quantitative controls, the same amount of template was used for all reactions.

The spacer sequences of Lactobacillus casei strain ATCC $393^{\mathrm{T}}$ were found to be distinct from the sequences of all the other Lactobacillus casei-related strains. These unique features lie in the length and sequence heterogeneity. Lactobacillus casei strain ATCC $393^{\mathrm{T}}$ has spacers 197 and $117 \mathrm{bp}$ in length while the others are 198 and $122 \mathrm{bp}$ long. The sequence of the LISR of strain ATCC 393 had only about 80.2\% similarity with the LISR of the other strains including Lactobacillus paracasei subsp. tolerans NCIMB $9709^{\mathrm{T}}$, and $72.4 \%$ for SISR with the data from the other strains. The deletion of the LISR is also different in that an $80 \mathrm{bp}$ deletion occurred between positions 24 and $104 \mathrm{bp}$ instead of a $76 \mathrm{bp}$ deletion between positions 17 and $93 \mathrm{bp}$ (as in the other strains). Several workers (Dicks et al., 1996; Dellaglio et al., 1991; Mori et al., 1997) have questioned the status of strain ATCC 393 as the type strain although the request for an opinion by Dellaglio et al. (1991) was denied by the judicial commission (Wayne, 1994). Their arguments were based on the low level of DNA homology with other strains of Lactobacillus casei subsp. casei (8$46 \%$ ) and strains of Lactobacillus paracasei (30-50\%), protein profile analysis and random amplified poly- 
morphic DNA (RAPD) results. On the other hand, Lactobacillus casei ATCC 334 was revealed to be genetically closely related to Lactobacillus casei subsp. casei (71-90\% DNA homology) and Lactobacillus paracasei $(71-91 \%)$ strains, to belong to the same protein profile cluster and to share several DNA amplicons with Lactobacillus paracasei strains in RAPD. The 23S-5S spacer sequence of strain ATCC 334 determined in this study showed $98-99.5 \%$ homology with the LISRs, 95.9-96.7\% with the SISRs of other strains in the group. The BamHI and PstI ribotypes of strain ATCC 393, as previously discussed, were distinct from the others in the group, while strain ATCC 334 shared high levels of similarity with them. These results therefore support the request of Dicks and his colleagues to replace strain ATCC 393 with strain ATCC 334 as the neotype of Lactobacillus casei subsp. casei.

The 23S-5S spacer sequences obtained in this study provide additional information for the taxonomic study of the Lactobacillus casei group. The ISR PCR profiles showed that the length polymorphisms correspond well to the proposed reclassification by Collins et al. (1989). Lactobacillus rhamnosus (NCIMB 6375 and ATCC 53103) had two different smaller sized bands; Lactobacillus paracasei subsp. tolerans type strain NCIMB $9709^{\mathrm{T}}$ yielded only one long spacer although the sequence was identical to the LISR sequence of strain NCIMB 8822. The length polymorphisms distinctively differentiate Lactobacillus rhamnosus and Lactobacillus casei subsp. tolerans strains from other strains in the group. Previously, the 16S rRNA sequence analysis was commonly used in taxonomy study. The 16S rRNA genes of strains of Lactobacillus casei JCM $181^{\mathrm{T}}$ (strain NCIMB 9713), Lactobacillus paracasei JCM $1133^{\mathrm{T}}$ (strain ATCC 27216), Lactobacillus paracasei subsp. tolerans JCM $1171^{\mathrm{T}}$ (strain NCIMB $9709^{\mathrm{T}}$ ) and Lactobacillus casei ATCC 334 were reported to be identical (Mori et al., 1997). A pair of primers (R16-2 and R23-1R) flanking the 16S-23S rRNA spacer region reported in a previous work (Nakagawa et al., 1994) was applied to the lactobacilli strains tested in our study. It was found that using primers R16-2 and R23-1R, all nine strains in our study yielded the same PCR profile of three major bands ranging in size from 270 to $490 \mathrm{bp}$. However, the PCR profiles or sequences of the $23 \mathrm{~S}-5 \mathrm{~S}$ rRNA spacers presented some interspecific variations. The sequence divergence of the 23S-5S ISR therefore allowed better taxonomic differentiation by PCRribotyping among the closely related strains of Lactobacillus casei-related species.

In the course of comparisons with the reported data on other 23S-5S spacer sequences of lactobacilli in GenBank, a fortuitous discovery was made. A high similarity of $98 \%$ was found between the short $23 \mathrm{~S}-5 \mathrm{~S}$ spacers of Lactobacillus casei-related strains and the 23S-5S ISR of strain Lactobacillus curvatus ARILAIT LC59 (GenBank no. Z75471). This sequence homology is consistent with the $16 \mathrm{~S}-23 \mathrm{~S}$ spacer association
(Berthier \& Enlrich, 1998). The 16S-23S spacer (GenBank no. Z75469) of this strain had very low similarity with the sequences determined in the Lactobacillus curvatus group, small spacer (GenBank no. U97132) $(67 \%)$ and large spacer (GenBank no. U97139) (75\%) regions. However, it shares 94.5$100 \%$ similarity with the $16 \mathrm{~S}-23 \mathrm{~S}$ spacer sequences of Lactobacillus casei, Lactobacillus rhamnosus and Lactobacillus paracasei reported in GenBank (GenBank nos U32964, U32966 and Z75479). It was then suggested that this Lactobacillus curvatus strain should be reclassified into the Lactobacillus casei group. The high level of 23S-5S ISR sequence homology between strain Lactobacillus curvatus LC59 and the sequences of the Lactobacillus casei strains in our study supports this suggestion. It is not known if a long spacer similar to that in the Lactobacillus casei strains is present in this Lactobacillus curvatus LC59 strain. To confirm this proposal, the $23 \mathrm{~S}-5 \mathrm{~S}$ rRNA ISRs of other Lactobacillus curvatus strains could be obtained and compared with the sequence of this strain.

No tRNA-like structures were identified within the 23S-5S regions of the strains tested in this study. The central regions of the $16 \mathrm{~S}-23 \mathrm{~S}$ ISRs of two groups of lactobacilli (i.e. one composed of Lactobacillus curvatus, Lactobacillus graminis and Lactobacillus sakei and another comprising Lactobacillus paraplantarum, Lactobacillus plantarum and Lactobacillus pentosus) were found to contain the genes of tRNA $\mathrm{Al}^{\text {Ile }}$ and tRNA ${ }^{\text {Ala }}$ (Nour, 1998). So far, there are no reports of the presence of any tRNA gene in the 23S-5S ISR in any bacterium. We argue that this could be responsible for a higher evolution rate for this non-functional spacer region, which possesses great variability in its sequence and length polymorphisms where deletion/ insertion and some random base substitutions occurred. In addition, the 23S-5S ISR sequences are smaller and easily sequenced. The sequences of the 23S-5S spacer provide reliable and easily derived information for inferring the closely related strains, which might not be detected or differentiated by $16 \mathrm{~S}$ rRNA or even $16 \mathrm{~S}-23 \mathrm{~S}$ spacer sequences. These data are also very useful in determining the taxonomic status of different strains within a species.

This work has demonstrated a polymorphism in the spacer sequences between the genes for the $23 \mathrm{~S}$ and $5 \mathrm{~S}$ rRNAs among bacteria in the Lactobacillus caseirelated group and has indicated its usefulness in identification. The ISR variabilities lie in the length and sequence polymorphisms, in which deletion/ insertion or single- and set-base substitutions occur. This makes it a valuable genetic marker, particularly for identification, for differentiation of closely realted strains and for phylogenetic analysis of unknown organisms.

\section{ACKNOWLEDGEMENTS}

One of the authors (H.C.) was supported by a National University of Singapore research scholarship. 


\section{REFERENCES}

Barry, T., Colleran, G., Glennon, M., Dunican, L. K. \& Gannon, F. (1991). The $16 \mathrm{~s} / 23 \mathrm{~s}$ ribosomal spacer region as a target for DNA probes to identify eubacteria. PCR Methods Appl 1, 51-56.

Berthier, F. \& Ehrlich, D. D. (1998). Rapid species identification within two groups of closely related lactobacilli using PCR primers that target the $16 \mathrm{~S} / 23 \mathrm{~S}$ rRNA spacer region. FEMS Microbiol Lett 161, 97-106.

Chevallier, B., Hubert, J.-C. \& Kammerer, B. (1994). Determination of chromosome size and number of rrn loci in Lactobacillus plantarum by pulsed-field gel electrophoresis. FEMS Microbiol Lett 120, 51-56.

Collins, M. D., Phillips, B. A. \& Zanoni, P. (1989). Deoxyribonucleic acid homology studies of Lactobacillus casei, Lactobacillus paracasei sp. nov., subsp. paracasei and subsp. tolerans, and Lactobacillus rhamnosus sp. nov., comb. nov. Int $J$ Syst Bacteriol 39, 105-108.

Collins, M. D., Rodrigues, U., Ash, C., Aguirre, M., Farrow, J. A. E., Martinez-Murcia, A., Phillips, B. A., Williams, A. M. \& Wallbanks, S. (1991). Phylogenetic analysis of the genus Lactobacillus and related lactic acid bacteria as determined by reverse transcriptase sequencing of $16 \mathrm{~S}$ rRNA. FEMS Microbiol Lett 77, 5-12.

Dellaglio, F., Dicks, L. M. T., Du Toit, M. \& Torriani, S. (1991). Designation of ATCC 334 in place of ATCC 393 ${ }^{\mathrm{T}}$ (NCDO $161^{\mathrm{T}}$ ) as the neotype strain of Lactobacillus casei subsp. casei and rejection of the name Lactobacillus paracasei (Collins et al. 1989). Request for an Opinion. Int J Syst Bacteriol 41, 340-342.

Dicks, L. M. T., Du Plessis, E. M., Dellaglio, F. \& Lauer, E. (1996). Reclassification of Lactobacillus casei subsp. casei ATCC $393^{\mathrm{T}}$ and Lactobacillus rhamnosus ATCC 15820 as Lactobacillus zeae nom. rev., designation of ATCC 334 as the neotype of L. casei subsp. casei, and rejection of the name Lactobacillus paracasei. Int J Syst Bacteriol 46, 337-340.

Ferrero, M., Cesena, C., Morelli, L., Scolari, G. \& Vescovo, M. (1996). Molecular characterization of Lactobacillus casei strains. FEMS Microbiol Lett 140, 215-219.

Frothingham, R. \& Wilson, K. H. (1994). Molecular phylogeny of the Mycobacterium avium complex demonstrates clinically meaningful divisions. J Infect Dis 169, 305-312.

Gürtler, V. \& Barrie, H. D. (1995). Typing of Staphylococcus aureus strains by PCR-amplification of variable-length $16 \mathrm{~S}-23 \mathrm{~S}$ rDNA spacer regions: characterization of spacer sequences. Microbiology 141, 1255-1265.

Gürtler, V. \& Stanisich, V. A. (1996). New approaches to typing and identification of bacteria using the $16 \mathrm{~S}-23 \mathrm{~S}$ rDNA spacer region. Microbiology 142, 3-16.

Hall, L. M. C. (1994). Are point mutations or DNA rearrangements responsible for the restriction fragment length polymorphisms that are used to type bacteria? Microbiology 140, 197-204.

Hertel, C., Ludwig, W., Pot, B., Kersters, K. \& Schleifer, K-H. (1993). Differentiation of lactobacilli occurring in fermented milk products by using oligonucleotide probes and electrophoretic protein profiles. Syst Food Microbiol 16, 463-467.

Higgins, D. G. \& Sharp, P. M. (1989). Fast and sensitive multiple sequence alignments on a microcomputer. CABIOS 5, 151-153.
Ish-Horowicz, D. \& Burke, J. F. (1981). Rapid and efficient cosmid cloning. Nucleic Acids Res 9, 2989-2998.

Jensen, M. A., Webster, J. A. \& Straus, N. (1993). Rapid identification of bacteria on the basis of polymerase chain reactionamplified ribosomal DNA spacer polymorphisms. Appl Environ Microbiol 59, 945-952.

Mori, K., Yamazaki, K., Ishiyama, T., Katsumate, M. \& Kobayashi, K. (1997). Comparative sequence analysis of the genes coding for 16S rRNA of Lactobacillus casei-related taxa. Int J Syst Bacteriol 47, 54-57.

Nakagawa, T., Shimada, M., Mukai, H., Asada, K., Kato, I., Fujino, K. \& Sato, T. (1994). Detection of alcohol-tolerant hiochi bacteria by PCR. Appl Environ Microbiol 60, 637-640.

Nour, M. (1998). $16 \mathrm{~S}-23 \mathrm{~S}$ and $23 \mathrm{~S}-5 \mathrm{~S}$ intergenic spacer regions of lactobacilli: nucleotide sequence, secondary structure and comparative analysis. Res Microbiol 149, 433-448.

Pebay, M., Colmin, C., Guedon, G., De Gasperi, C., Decaris, B. \& Simonet, J. M. (1992). Detection of intraspecific DNA polymorphism in Streptococcus salivarius subsp. thermophilus by a homologous rDNA probe. Res Microbiol 143, 37-46.

Roussel, Y., Colmin, C., Simonet, J. M. \& Christiansen, C. (1987). Analysis of the leader and spacer regions of the two rRNA operons of Mycoplasma PG50: two tRNA genes are located upstream of rrn A. Mol Gen Genet 208, 23-29.

Sambrook, J., Fritsch, E. F. \& Maniatis, T. (editors) (1989). Molecular Cloning : a Laboratory Manual, 2nd edn, vol. 1, pp. 1.53-1.73. Cold Spring Harbor, NY: Cold Spring Harbor Laboratory.

Stahl, M., Molin, G., Persson, A., Ahrne, S. \& Stahl, S. (1990). Restriction endonuclease patterns and multivariate analysis as a classification tool for Lactobacillus spp. Int J Syst Bacteriol 40, 189-193.

Tilsala-Timisjarvi, A. \& Alatossava, T. (1997). Development of oligonucleotide primers from the $16 \mathrm{~S}-23 \mathrm{~S}$ rRNA intergenic sequences for identifying different dairy and probiotic lactic acid bacteria by PCR. Int J Food Microbiol 35, 49-56.

Tulloch, D. L., Finch, L. R., Hillier, A. J. \& Davidson, B. E. (1991). Physical map of the chromosome of Lactococcus lactis subsp. lactis DL11 and localization of six putative rRNA operons. $J$ Bacteriol 173, 2768-2775.

Wayne, L. G. (1994). Action of the Judicial Commission of the International Committee on Systematic Bacteriology on Requests for Opinions published between 1991 and 1992. Int J Syst Bacteriol 44, 177-178.

Whiley, R. A., Duke, B., Hardie, M. \& Hall, M. C. (1995). Heterogeneity among 16S-23S rRNA intergenic spacers of species within the 'Streptococcus milleri group'. Microbiology 141, 1461-1467.

Yoon, J.-H., Lee, S. T., Kim, S.-B., Goodfellow, M. \& Park, Y.-H. (1997). Inter- and intraspecific genetic analysis of the genus Saccharomonospora with $16 \mathrm{~S}$ to $23 \mathrm{~S}$ ribosomal DNA (rDNA) and $23 \mathrm{~S}$ to $5 \mathrm{~S}$ rDNA internally transcribed spacer sequences. Int $J$ Syst Bacteriol 47, 661-669.

Zhong, W., Millsap, K., Bialkowska-Hobrzanska, H. \& Reid, G. (1998). Differentiation of Lactobacillus species by molecular typing. Appl Environ Microbiol 64, 2418-2423.

Zhu, Q., Lim, C. K. \& Chan, Y. N. (1996). Detection of Salmonella typhi by polymerase chain reaction. J Appl Bacteriol $\mathbf{8 0}$, 224-251. 